\title{
PPT Development for Nanosatellite Applications: Experimental Results
}

\author{
Michele Coletti, Simone Ciaralli, and Stephen B. Gabriel
}

\begin{abstract}
In this paper, the design and performances of a pulsed plasma thruster (PPT) for nanosatellite applications will be presented. The breadboard model PPT presented in this paper will be a part of six PPTs propulsion system designed to provide attitude and translational control for a $20-\mathrm{kg}$ nanosatellite for a total delta-V of $40 \mathrm{~m} / \mathrm{s}$. The thruster performances have been characterized in terms of electrical parameters, mass bit, impulse bit, and specific impulse. The thruster was found to be compliant with the mission requirement. Moreover, preliminary electromagnetic noise interference measurements have been performed. The spark plug discharge was found to be the main source of noise as already found by previous authors. From the collected data, it can be inferred that the noise is mostly radiated.
\end{abstract}

Index Terms-Propulsion, space technology.

\section{NOMENCLATURE}

A Propellant area exposed to the discharge.

$B \quad$ Magnetic field.

$C$ Capacitance.

E Energy.

$E / A \quad$ Energy density.

EMI Electromagnetic interference.

$g_{0} \quad$ Gravitational acceleration.

HV High voltage.

I Discharge current.

Ibit Impulse bit.

Isp Specific impulse.

$L \quad$ Inductance.

LV Low voltage.

PSD Power spectral density.

$R \quad$ Resistance.

rms Root mean square.

$\Psi \quad$ Current parameter.

$\varepsilon \quad$ Electric field.

\section{INTRODUCTION}

$\mathbf{T}$ HERE is a growing technical interest for the use of nanosatellites within the aerospace community. However,

Manuscript received November 29, 2013; revised October 15, 2014; accepted November 3, 2014. Date of publication November 4, 2014; date of current version January 6, 2015. This work was supported by the European Space Agency-European Space Research and Technology Centre under Contract 4000101343/10/NL/SFe.

M. Coletti is with Mars Space Ltd., Southampton SO14 5FE, U.K. (e-mail: michele.coletti@mars-space.co.uk).

S. Ciaralli is with the Department of Electronics and Computer Science, University of Southampton, Southampton SO17 1BJ, U.K. (e-mail: sc2d11@soton.ac.uk).

S. B. Gabriel is with the Astronautics Research Group, University of Southampton, Southampton SO17 1BJ, U.K. (e-mail: sbg2@ soton.ac.uk).

Color versions of one or more of the figures in this paper are available online at http://ieeexplore.ieee.org.

Digital Object Identifier 10.1109/TPS.2014.2368054 the extent to which nanosatellites will be disruptive will depend heavily on the availability of suitable miniaturized propulsion systems. Due to resource limitations on nanosatellites, such as mass, volume, and power, a new generation of micropropulsion systems is needed. A consortium formed by the University of Southampton, Mars Space Ltd., Clyde Space Ltd., OHB Sweden, and NanoSpace has performed a survey of the potential mission classes, which could benefit from the use of a microthruster module and a tradeoff leading to the selection of the most promising propulsion technology to develop [1]. At the end of this tradeoff, pulsed plasma thruster (PPT) technology was selected and a thruster designed and manufactured [2]. In this paper, the mission requirements and the thruster design will be briefly presented, after this the results obtained during the test campaign in terms of current parameter $(\Psi)$, mass ablated per shot (mass bit, mbit), impulse delivered per shot (impulse bit, Ibit), specific impulse (Isp), will be reported in detail and compared with the mission requirements. In an attempt to obtain experimental results that could be used in the future to optimize the thruster, measurements were performed outside of the nominal working conditions of the PPT in a shot energy range going from 3 to $5.5 \mathrm{~J}$ and reaching $2 \mathrm{~J}$ for mass bit and impulse bit measurements.

After this, a set of preliminary measurements of the thruster EM noise will be presented together with a discussion of the most likely sources of this noise.

\section{Mission REQUiREMENTS}

For the definition of the mission requirements, several kinds of nanosatellite missions that can benefit from the use of micropropulsion have been addressed [3]-[10]. This review revealed that a micropropulsion system for nanosatellites should be able to perform a variety of maneuvers including but not limited to orbit maintenance, station keeping, attitude control, and formation flying. The system should be comprised of up to 12 thrusters with a power consumption per thruster of $<10 \mathrm{~W}$ and should be able to deliver values of delta- $\mathrm{V}(\Delta V)$ of the order of 10 to $100 \mathrm{~m} / \mathrm{s}$ [1].

For the scope of this activity, it was decided to design a micropropulsion system able to provide attitude and translational control for a $20-\mathrm{kg}$ nanosatellite for a total $\Delta V$ of $40 \mathrm{~m} / \mathrm{s}$. The system will be comprised of six PPTs, each of which will have a wet mass $<500 \mathrm{~g}$. The power consumption of each thruster has been limited to a maximum of $10 \mathrm{~W}$ and the volume available to $0.0016 \mathrm{~m}^{3}$ [1]. The propulsion module requirements are summarized in Table I, where it has 
TABLE I

PROPULSION SYSTEM REQUIREMENTS

\begin{tabular}{ccc}
\hline \hline Requirement & Propulsion system & Single thruster unit \\
\hline$\Delta \mathrm{V}$ & $40 \mathrm{~m} / \mathrm{s}$ & \\
Total impulse & $800 \mathrm{Ns}$ & $133 \mathrm{Ns}$ \\
Number of thrusters & 6 & \\
Max Volume & & $0.0016 \mathrm{~m} 3$ \\
Max wet mass & $3 \mathrm{~kg}$ & $500 \mathrm{~g}$ \\
Max Power consumption & & $10 \mathrm{~W}$ \\
\hline \hline
\end{tabular}

been assumed that the total impulse requirement is evenly split among the six thrusters.

\section{Pulsed Plasma Thruster Design}

After completing a tradeoff comparing the most promising propulsion technologies for nanosats, it was decided to design a breech-fed pulsed plasma thruster [1], [2]. Considering the power available and aiming at a pulse frequency of $\sim 1 \mathrm{~Hz}$, a discharge energy of $5 \mathrm{~J}$ was selected. The discharge energy density, i.e., the ratio between the discharge energy and the propellant surface exposed to the discharge ( $E / A$ ratio), has been fixed at $2.5 \mathrm{~J} / \mathrm{cm}^{2}$ to obtain good performances at the same time allowing a compact thruster design. Considering the selected $E / A$, an Isp of $550 \mathrm{~s}$ is expected according to [11]. By considering this value, the required total impulse and applying a $20 \%$ margin on the propellant mass, a total of $30 \mathrm{~g}$ of PTFE will be used as propellant in each PPT.

The PPT electrodes have been manufactured using a copper tungsten alloy; they will have a spacing of $2 \mathrm{~cm}$ and a width of $1 \mathrm{~cm}$ resulting in a $h / w$ ratio identical to the one used in PPTCUP [12]. The electrodes are about 2-cm long and, in an attempt to improve performances, they are tongue-shaped and flared at $20^{\circ}$ [13]. The spark plug uses a copper electrode surrounded by a thin ring of PTFE delivering reliable discharge ignition at a voltage of $\sim 8 \mathrm{kV}$ in line with what has been successfully used in the PPTCUP lifetime test [14].

The discharge energy is stored in a capacitor bank made of 20 ceramic capacitors charged at a nominal voltage of $1720 \mathrm{~V}$ (equivalent to $5 \mathrm{~J}$ of energy). The capacitors used are the same that were successfully tested to 1800000 discharges in the frame of the PPTCUP lifetime verification [14]. The assembled PPT, which has an envelope of $\sim 110 \times 30 \times 45 \mathrm{~mm}^{3}$, is shown in Fig. 1.

The electronics board that is used to command and monitor the PPT has been designed and manufactured by Clyde Space Ltd. The electronics is split over two boards (Fig. 2): 1) containing the RS-485 communication interface used to communicate with the satellite and 2) containing the HV circuitry needed to deliver the required capacitor bank and spark plug voltage.

To allow for performance investigation the capacitor charge voltage can be varied in the range $900-1850 \mathrm{~V}$ via the RS-485 interface. The spark plug voltage is instead fixed at $8 \mathrm{kV}$.

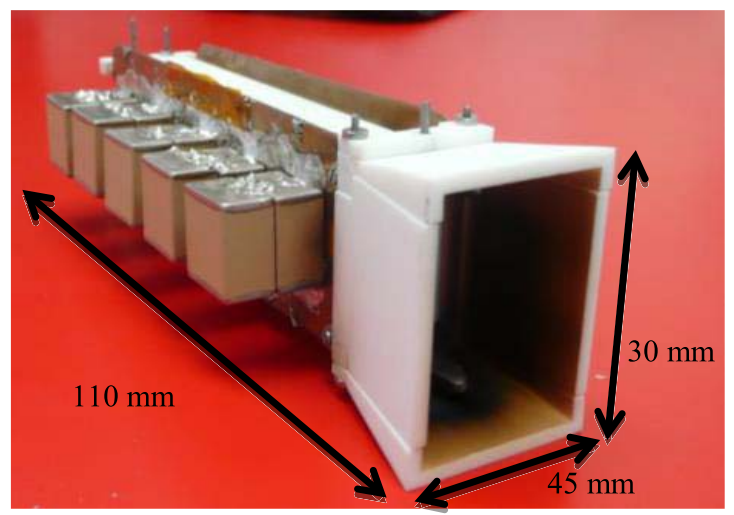

Fig. 1. Assembled breech-fed PPT.

a)

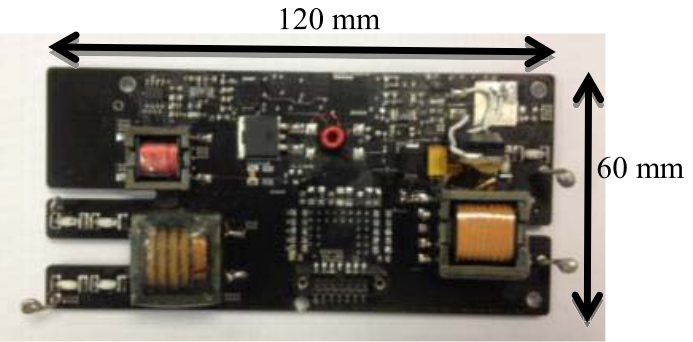

b)

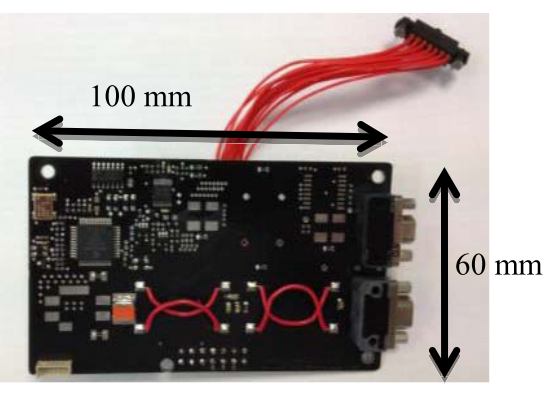

Fig. 2. PPT electronics. (a) HV board. (b) Digital board for communications and telemetry.

The electronics board assembly has an overall mass of $\sim 100 \mathrm{~g}$ and an envelope of $\sim 120 \times 60 \times 30 \mathrm{~mm}^{3}$.

\section{Test CAMPAign}

The main aim of the experimental campaign was to verify the thruster performance against the requirements. Nevertheless, to obtain more data that can be used in the future for thruster optimization, it was decided to perform testing over a wide range of energies (from 2 to $5.5 \mathrm{~J}$ ).

The thruster has been tested in two different configurations for a range of discharge energies. The first configuration (the nominal configuration reported in Fig. 3(a) has the capacitor bank mounted as close as possible to the thruster body to minimize the parasitic inductance and improve the thruster performances and it does not allow the use of Rogowski coils. In the second configuration [wide bank configuration shown in Fig. 3(b)], the capacitor bank has been displaced from the thruster body to allow current monitoring via the incorporation of Rogowski coils between the capacitor bank and the electrodes. 
TABLE II

PPT DESIGN PARAMETERS

\begin{tabular}{cc|cc}
\hline \hline PTFE bar geometry & $\begin{array}{c}\text { Breech } \\
\text { fed }\end{array}$ & Thruster wet mass & $240 \mathrm{~g}$ \\
PTFE mass & $30 \mathrm{~g}$ & Electronics mass & $100 \mathrm{~g}$ \\
PTFE bar length & $6.8 \mathrm{~cm}$ & $\begin{array}{c}\text { Total wet mass } \\
\text { Electronics power } \\
\text { output }\end{array}$ & $340 \mathrm{~g}$ \\
Required Isp & $550 \mathrm{~s}$ & $5 \mathrm{~W}$ \\
$\begin{array}{c}\text { Discharge energy } \\
\text { Nominal capacitor } \\
\text { charge voltage }\end{array}$ & $5 \mathrm{~J}$ & $\begin{array}{c}\text { Electronics Efficiency } \\
\text { Electronics capacitor } \\
\text { bank charge voltage }\end{array}$ & $\begin{array}{c}275 \% \\
\text { Bank capacitance (not } \\
\text { including derating) }\end{array}$ \\
$E / A$ & $4 \mu \mathrm{F}$ & $\begin{array}{c}\text { Electronics spark plug } \\
\text { voltage }\end{array}$ & $8 \mathrm{kV}$ \\
\hline \hline
\end{tabular}
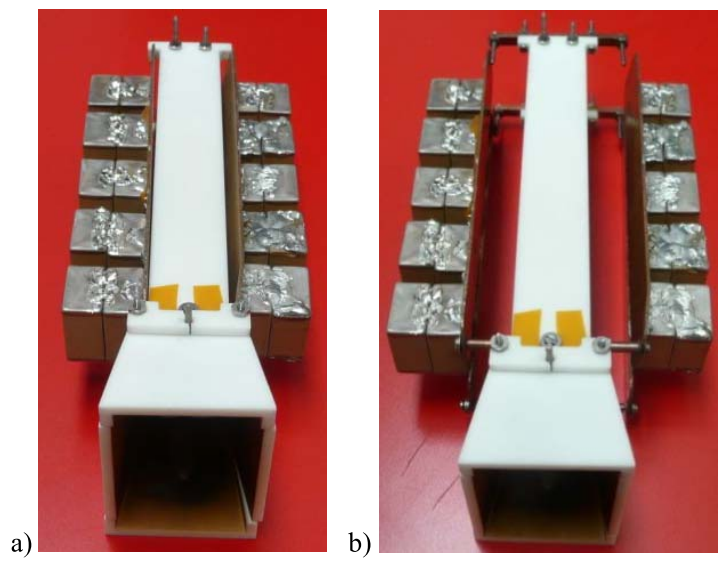

Fig. 3. PPT with $4-\mu \mathrm{F}$ capacitor bank. (a) Nominal configuration. (b) Wide bank configuration.

TABLE III

PPT TEST MATRIX

\begin{tabular}{lcc}
\hline \hline Configuration & \multicolumn{2}{c}{ Measurements } \\
\hline "nominal" & Voltage curves & Mass bit \\
& Impulse bit & EM noise \\
\hline "wide bank" & Voltage curves & Current curves \\
\hline \hline
\end{tabular}

During the test campaign, current and voltage curves, impulse bit (Ibit), mass bit (mbit), and EM noise have been measured. The measurements performed in each configuration are reported in Table III.

\section{Test Setup}

The test campaign was carried out at the University of Southampton. The vacuum chamber used is a stainless steel vertical cylinder with an internal volume of $0.35 \mathrm{~m}^{3}$. It has six $\mathrm{CF}$ flanges where the electrical F/Ts are installed and a $0.5-\mathrm{m}$ diameter circular main port on the side surface. The vacuum chamber is evacuated by a pumping system comprised of an Edwards roughing pump and by a Pfeiffer Balzers TPH 450-H turbo molecular pump with a pumping speed of $450 \mathrm{l} / \mathrm{s}$ backed

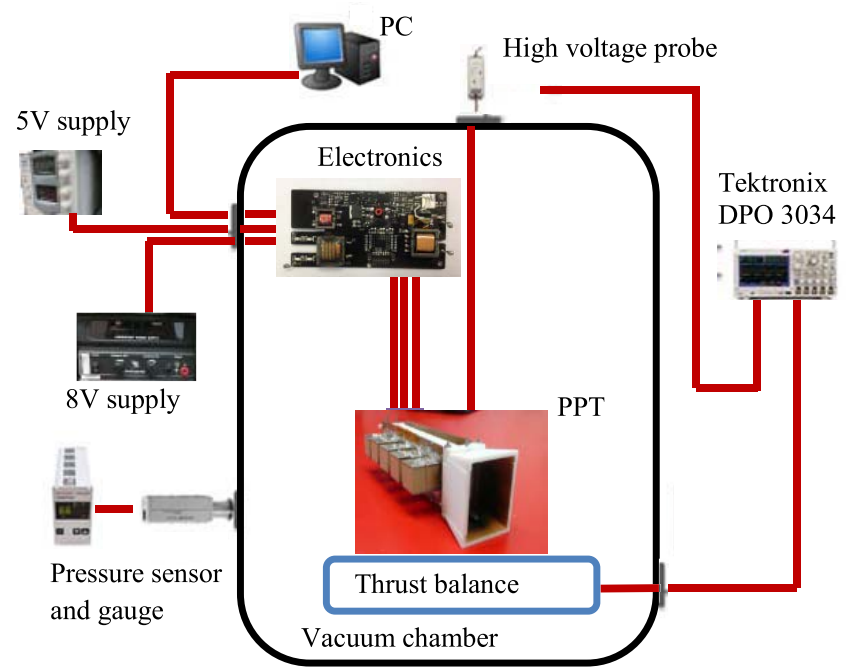

Fig. 4. Physical test setup.

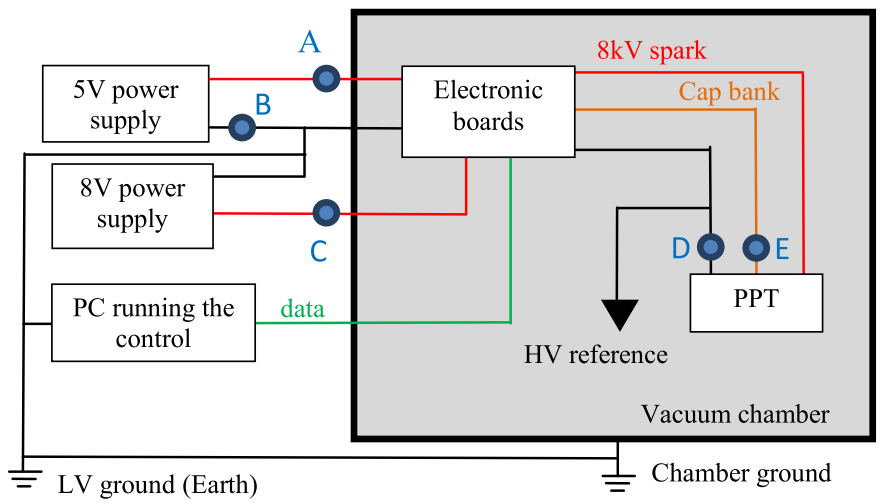

Fig. 5. Electrical test setup.

by a MD4TC Vacuubrand membrane pump achieving a base pressure of about $5 \mathrm{E}-6$ mbar.

The physical and electrical test setups are reported in Figs. 4 and 5.

The thruster impulse bit was measured with a direct impulsive thrust balance developed in-house; a more detailed description of the balance can be found in [15]. The thruster mass consumption has been measured using a Mettler Toledo balance with an accuracy of $\pm 5 \mu \mathrm{g}$ and performing a minimum of 300 shots per energy level (1000 shots at energy levels below $3.5 \mathrm{~J}$ ) achieving a measurement error of $<3 \%$. Once Ibit and mbit are measured, the Isp value can be calculated using

$$
\mathrm{Isp}=\frac{\mathrm{Ibit}}{\mathrm{mbit} \cdot \mathrm{g}_{0}}
$$

where $g_{0}=9.81 \mathrm{~m} / \mathrm{s}^{2}$.

It must be noted that during the whole test campaign, the electronics LV ground and the chamber ground were always connected to Earth, whereas the HV potential reference has been left floating and insulated from the LV ground. With reference to Fig. 5, test point $D$ and $E$ were used to perform the discharge voltage measurements, whereas test points $A, B$, and $C$ were used during the EM noise measurements. 


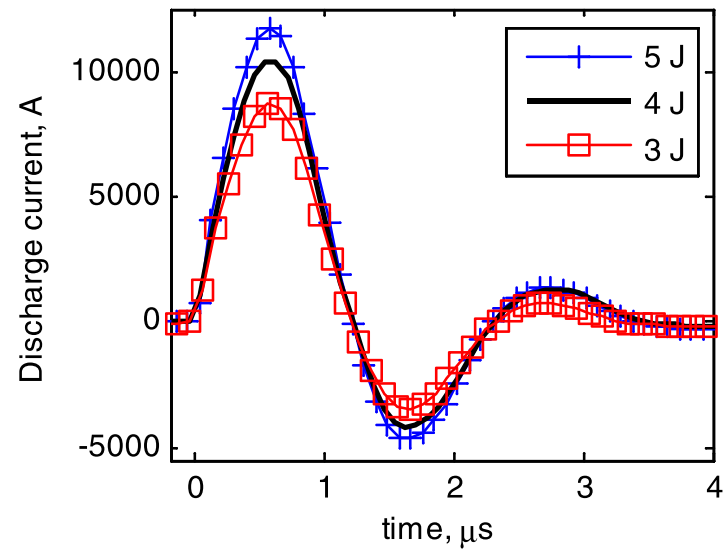

Fig. 6. Discharge current curves (wide bank configuration).

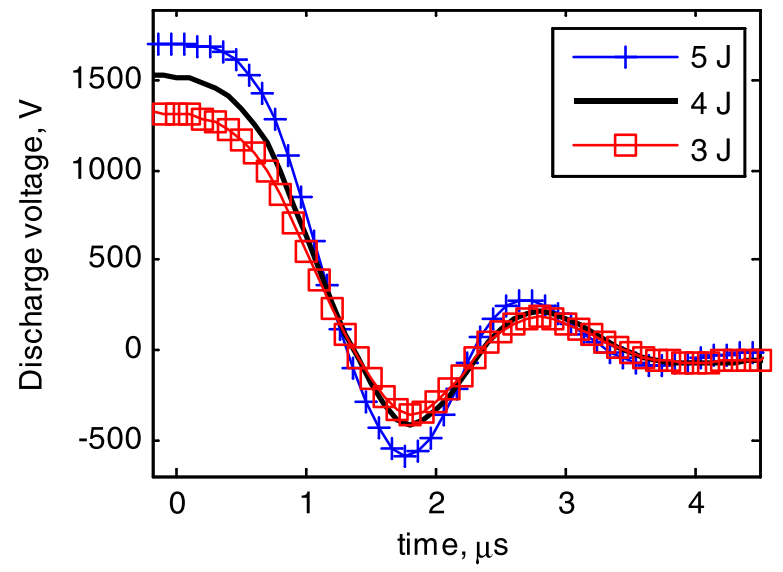

Fig. 7. Discharge voltage curves (wide bank configuration).

\section{EXPERIMENTAL RESUlts}

As already explained, the test campaign had the aim of both verifying that the PPT design will meet the requirements highlighted in Tables I and II and gathering experimental data that can be used in the future to optimize the design. All the data collected will be reported below and commented according to both the experimental campaign aims.

\section{A. Electrical Characteristics}

The first test that was performed had the purpose to characterize the thruster electrically. For each discharge energy, 10 shots were performed and the discharge voltage and current curves acquired; then, the data were averaged. The discharge voltage and current curves for the wide bank configuration are reported in Figs. 6 and 7 for various energies.

The nanosat PPT showed an under damped discharge behavior that expires in $\sim 1.5 \mathrm{~Hz}$ similar to the one that was measured on a Cubesat PPT developed previously [12].

From the discharge current values $(I)$, it is possible to calculate the discharge current parameter $(\Psi)$, defined as

$$
\Psi=\int_{0}^{\infty} I^{2} d t
$$

The current parameter trend with shot energy is shown in Fig. 8. The thruster also showed a very repeatable

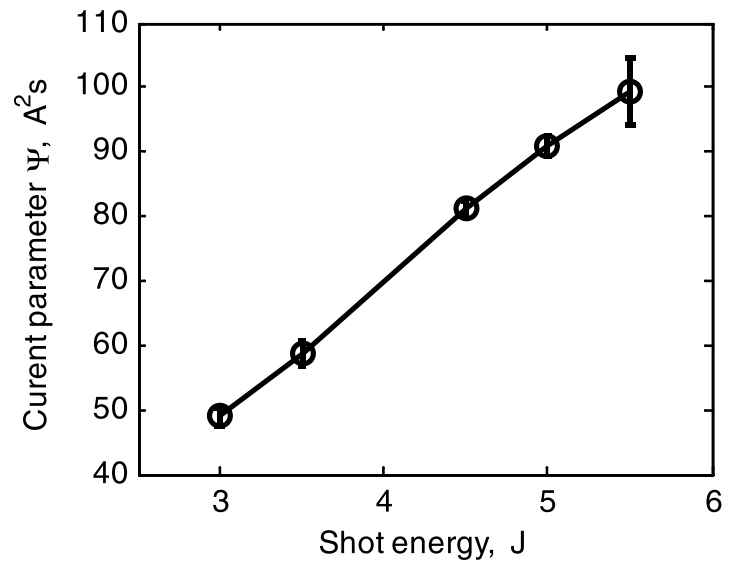

Fig. 8. $\Psi$ trend with shot energy (wide bank configuration).

TABLE IV

PPT ElECTRICAL PARAMETERS

\begin{tabular}{cccc}
\hline \hline Configuration & $\mathrm{R}[\mathrm{m} \Omega]$ & $\mathrm{L}[\mathrm{nH}]$ & $\mathrm{C}[\mu \mathrm{F}]$ \\
\hline "wide bank" & 56 & 41.5 & 4 \\
\hline
\end{tabular}

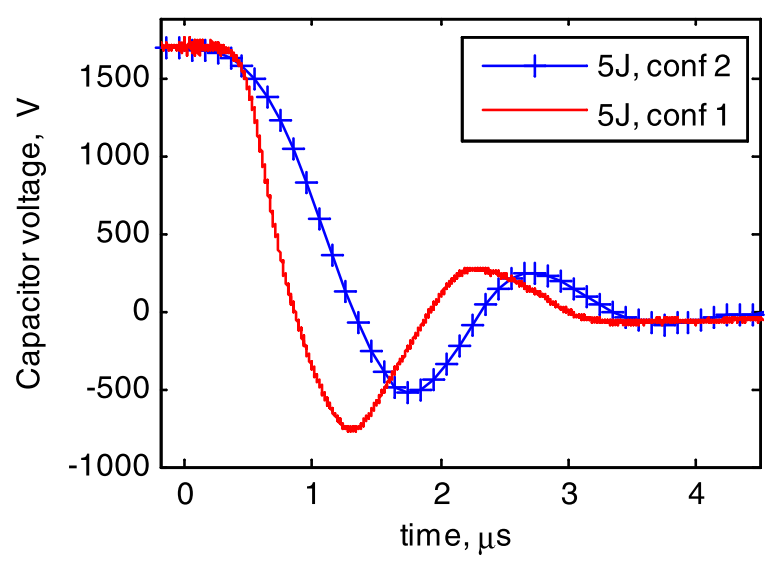

Fig. 9. Comparison of the typical discharge voltage curves for the nominal and wide bank configurations.

functioning with a standard deviation values for $\Psi$ of $<2 \%$ over the full range of energies that were tested.

The analysis of the discharge curves has been performed by fitting the acquired data with the classic under-damped solution of a $R L C$ circuit [12]. The estimated average PPT electrical parameters are reported in Table IV.

Regarding the electrical characterization of the nominal configuration, only the discharge voltage curves were acquired since it was impossible to fit the Rogowski coils as already explained in Section IV. The voltage curves so obtained are qualitatively similar to those in Fig. 7. The only significant difference is a reduction in the discharge time due to the reduced inductance of configuration 1 in comparison to configuration 2 (Fig. 3). Comparing the voltage curves relative to configurations 1 and 2 (Fig. 9), a reduction in inductance of $\sim 30 \%$ can be calculated based on the reduction in the discharge period and by assuming that the resistance is constant and equal to the value in Table IV. 


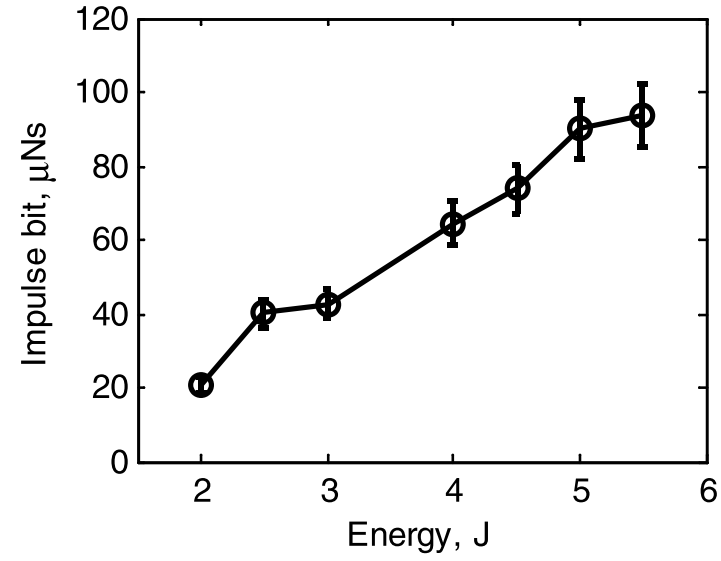

Fig. 10. Impulse bit trend with energy.

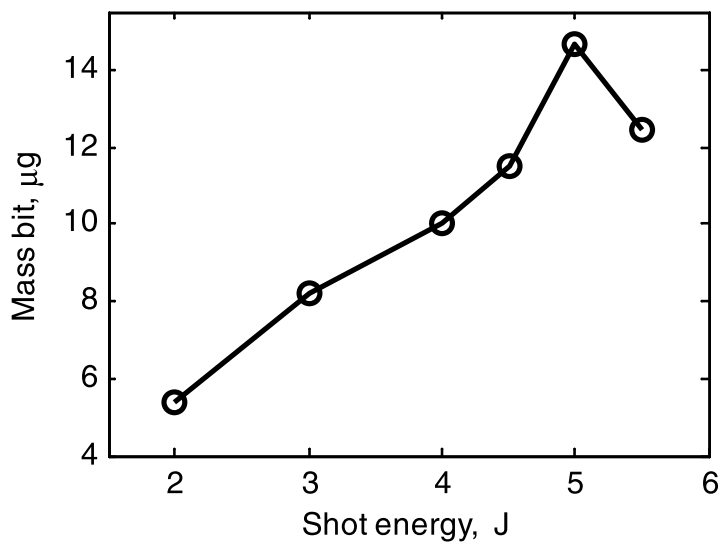

Fig. 11. Ablated mass bit trend with energy. Error bars are not shown because they would not be visible.

\section{B. Impulse Bit}

The impulse bit trend with the energy is shown in Fig. 10. For each energy value, 10 Ibit measurements were taken and then averaged. These measurements were performed after the thruster had completed $\sim 1000$ shots.

During these tests, the PPT delivered very repeatable performances as the standard deviations of the impulse bit values were $<3 \%$. It must be noted that the error bars in Fig. 10 include also the balance measurements error that has been quantified to be $\sim 8 \%$ [17].

Moreover, as shown in Fig. 10, the PPT delivers an Ibit of $\sim 90 \pm 8.1 \mu \mathrm{Ns}$ at $5 \mathrm{~J}$ with an Ibit/ $E$ ratio of $\sim 18 \pm 1.6 \mu \mathrm{Ns} / \mathrm{J}$ in line with the typical performances of breech fed pulsed plasma thrusters [16].

\section{Mass Bit and Specific Impulse}

The mass bit trend with energy is reported in Fig. 11 and the Isp values derived according to (1) are shown in Fig. 12.

As can be noted in Fig. 11, the mass bit shows an unusual peak at $5 \mathrm{~J}$ of energy. This measurement has been repeated twice (performing a total of 600 shots) but the results obtained did not change appreciably. It has to be noted that also the value of Ibit measured at $5 \mathrm{~J}$ is higher than the linear fit determined by the measurements at the other energy values (Fig. 10). This explains why the resulting Isp value

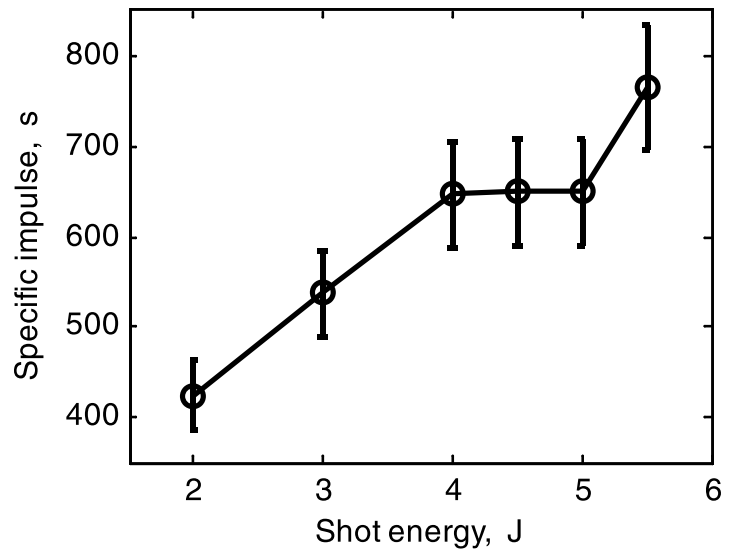

Fig. 12. Specific impulse trend with energy.

does not differ significantly from what is expected based on measurements at the other energy levels.

Looking at Fig. 12, it can be noted that the specific impulse value at the nominal energy of $5 \mathrm{~J}$ is $\sim 650 \pm 56 \mathrm{~s}$, which is $18 \%$ higher than the requirement of $550 \mathrm{~s}$ in Table II.

\section{Electromagnetic Interference (EMI)}

The last part of the experimental campaign was aimed at performing preliminary measurements of the EM noise produced by the PPT. Since no requirement was set on the PPT EMI levels at the beginning of the study, the aim of this test was to preliminarily characterize such levels. Moreover, to the authors' best knowledge most of the papers in the PPT literature do not deal with the EM noise produced by PPTs. The papers that treated EM noise [18]-[25] mostly present experimental measurements that refer to discharge energies that are about one order of magnitude higher than the one presented in this paper [19], [20], hence this test might provide data that might improve the understanding of EM noise production in low energy discharge PPTs.

For this test, it was decided to measure the voltage ripple on the digital $(5 \mathrm{~V})$ and power $(8 \mathrm{~V})$ lines going to the PPT electronics across points $A$ and $B$, and $C$ and $B$ in Fig. 5. It must be noted that for these measurements (as for the rest of the test campaign), the power supplies and vacuum chamber were grounded to Earth, whereas the PPT was left floating (meaning that the PPT cathode was not connected to Earth).

Measurements were performed only at energies close to the PPT nominal energy of $5 \mathrm{~J}$. In addition to this, measurements were also performed on these lines for a spark plug-only shot. The measured data is summarized in Table $\mathrm{V}$ where the rms value has been obtained averaging fifteen shots.

Looking at the data reported in Fig. 13, it can be noted that the noise generated by the PPT lasts for $\sim 400-500 \mathrm{~ns}$, hence the rms values reported in Table $\mathrm{V}$ have been calculated during this time.

Moreover, the data in Table $\mathrm{V}$ and Fig. 15 show that the shot energy influence on the noise rms level is very limited. In particular, the change in noise level with energy is normally within the measurement error bars. More importantly, it can be seen how the noise level measured on the 5 and $8 \mathrm{~V}$ lines 
TABLE V

RMS NOISE VALUES AT DIFFERENT ENERGIES

\begin{tabular}{cccc}
\hline $\begin{array}{c}\text { Cap bank voltage } \\
{[\mathrm{V}]}\end{array}$ & Energy [J] & Measurements & $\begin{array}{c}\text { Mean RMS value } \\
{[\mathrm{V}]}\end{array}$ \\
\hline 1632 & 4.5 & $8 \mathrm{~V}$ line & $2.27+/-0.63$ \\
1720 & 5 & $8 \mathrm{~V}$ line & $2.73+/-0.69$ \\
1804 & 5.5 & $8 \mathrm{~V}$ line & $2.51+/-0.72$ \\
0 & Spark only & $8 \mathrm{~V}$ line & $3.88+/-0.66$ \\
1632 & 4.5 & $5 \mathrm{~V}$ line & $2.44+/-0.59$ \\
1720 & 5 & $5 \mathrm{~V}$ line & $2.91+/-0.51$ \\
1804 & 5.5 & $5 \mathrm{~V}$ line & $2.7+/-0.61$ \\
0 & Spark only & $5 \mathrm{~V}$ line & $4.25+/-0.59$ \\
\hline \hline
\end{tabular}

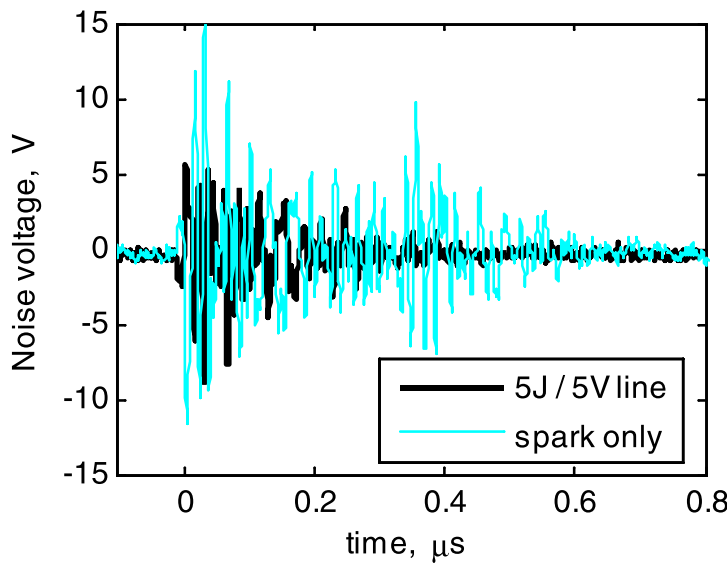

a)

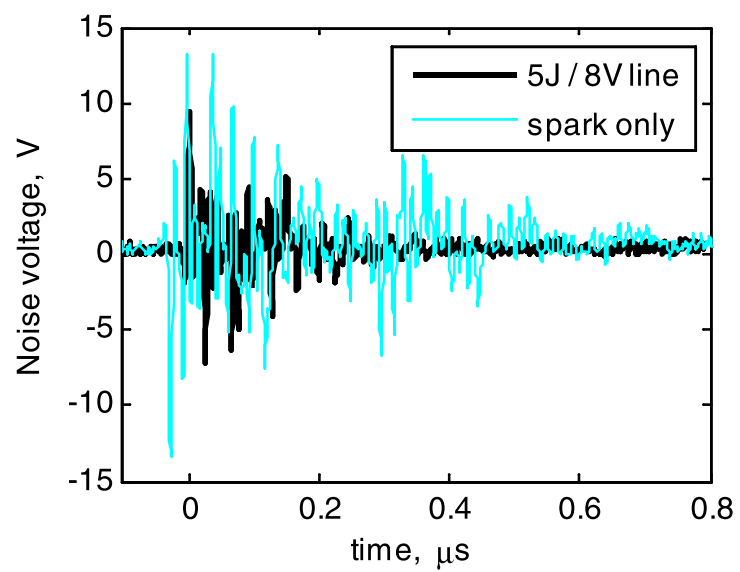

b)

Fig. 13. Comparison between the noise generated only by the spark plug and the one generated at $5 \mathrm{~J}$ of discharge energy. (a) Measured on the $8 \mathrm{~V}$ line. (b) Measured on the $5 \mathrm{~V}$ line.

are very similar and follow the exact same trend with energy. Moreover, a spark only shot (meaning that the spark plug is triggered without charging the main capacitor bank) produces a noise that is higher than the one produced by a complete thruster shot (meaning that the spark plug is fired with the capacitor bank charged, triggering the main discharge and producing the performances reported in Sections VI-A-VI-C).

During this test phase, attempts were made at acquiring the noise generated on the 5 and $8 \mathrm{~V}$ lines by a capacitor only discharge (meaning by a capacitor discharge generated without the use of the spark plug). Arcs were generated charging the

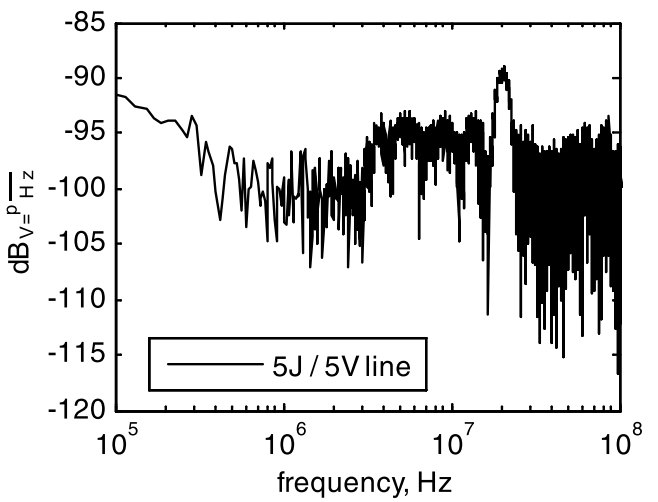

a)
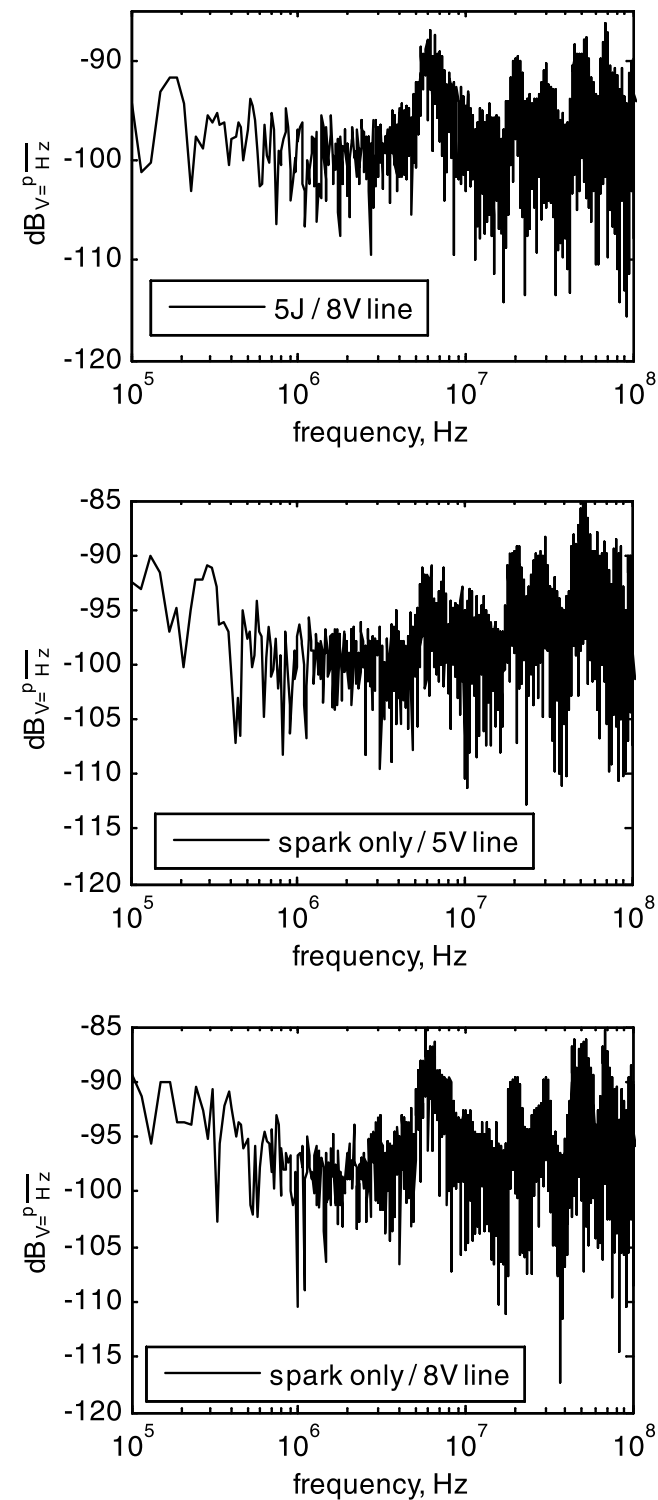

d)

Fig. 14. Noise PSD. (a) 5-J shot on the $5 \mathrm{~V}$ line. (b) 5-J shot on the $8 \mathrm{~V}$ line. (c) Spark plug only on the $5 \mathrm{~V}$ line. (d) Spark plug only on the $8 \mathrm{~V}$ line.

capacitor bank at $5 \mathrm{~J}$ of energy and increasing the chamber pressure until an arc across the capacitor bus bars occurred. Interestingly, no noise was detected by the scope.

Looking at the noise PSDs (Fig. 14), it can be seen how most of the noise power density is concentrated on frequencies 


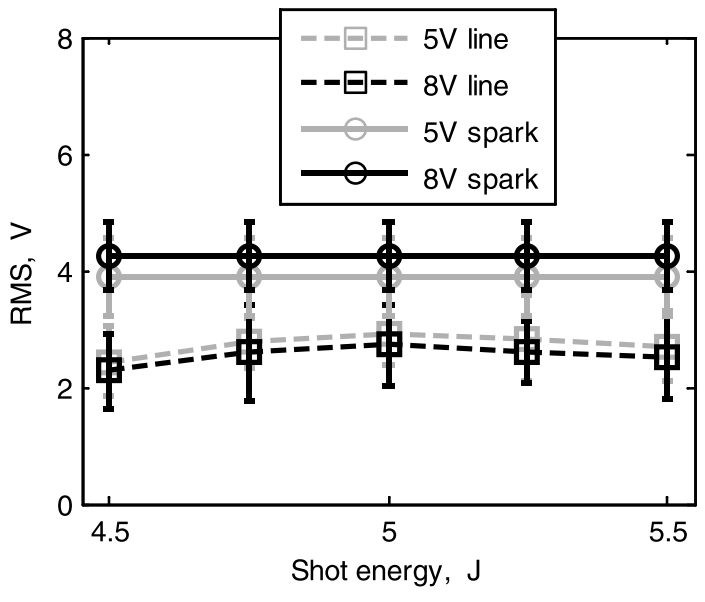

Fig. 15. RMS noise levels at different energies and for spark only operation on the 5 and $8 \mathrm{~V}$ lines.

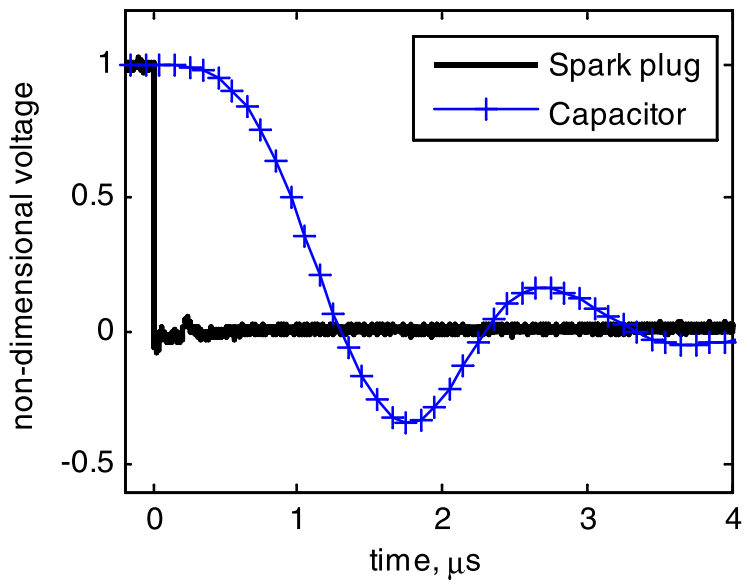

Fig. 16. Comparison between the normalized discharge voltage curve of the capacitor bank and the spark plug pulse.

close to $20 \mathrm{MHz}$ on the $5 \mathrm{~V}$ line and $6 \mathrm{MHz}$ on the $8 \mathrm{~V}$ line, from which it can be inferred that, as expected, a significant part of the noise will be radiated.

It can also be noted that there are qualitative similarities between the PSD obtained with a thruster shot at $5 \mathrm{~J}$ and the ones obtained with a spark plug only shot. This provides another argument in support of the conclusion according to which the spark plug is the main source of noise in this particular PPT design.

Considering that the spark plug energy is $\sim 10 \mathrm{~mJ}$ (hence significantly lower than the discharge energy), the fact that it is the main source of noise might seem unexpected. Nevertheless this can be explained looking at the characteristic discharge times of the spark plug and of the main discharge voltage traces reported in Fig. 16. The characteristic time of the main discharge is of the order of $1 \mu$ s whereas the one of the spark plug is significantly lower. In particular, the voltage traces reported in Fig. 16 have been acquired with a $100-\mathrm{MHz}$ bandwidth probe and the spark discharge proved to be too quick to be resolved by the probe, implying a discharge time $\sim 10 \mathrm{~ns}$. According to Maxwell-Faraday equation $\nabla \times \varepsilon=-\partial B / \partial t$, the EM noise is mainly generated by the
TABLE VI

REQUiREMENTS COMPLIANCE MATRIX

\begin{tabular}{cccc}
\hline \hline Requirement description & $\begin{array}{c}\text { Requirement } \\
\text { Value }\end{array}$ & $\begin{array}{c}\text { Measured } \\
\text { Value }\end{array}$ & Compliant \\
\hline $\begin{array}{c}\text { Micro thruster module } \\
\text { wet mass }\end{array}$ & $500 \mathrm{~g}$ & $350 \mathrm{~g}$ & Yes \\
Power & $<10 \mathrm{~W}$ & $5 \mathrm{~W}$ & Yes \\
Max Volume & $0.0016 \mathrm{~m}^{3}$ & $0.000324 \mathrm{~m}^{3}$ & Yes \\
Isp & $550 \mathrm{~s}$ & $640 \mathrm{~s}$ & Yes \\
$\Delta \mathrm{V}$ & $40 \mathrm{~m} / \mathrm{s}$ & $56 \mathrm{~m} / \mathrm{s}^{*}$ & Yes \\
$\begin{array}{c}\text { Total Impulse (for } 6 \\
\text { modules) }\end{array}$ & $800 \mathrm{Ns}$ & $1130 \mathrm{Ns} *$ & Yes \\
\hline \hline
\end{tabular}

*(based on $30 \mathrm{~g}$ propellant and measured Isp)

change in time of the magnetic field. Therefore, since the characteristic time of the spark plug pulse is at least two orders of magnitude smaller than that of the main discharge, it appears reasonable to affirm that the spark plug is the main source of noise. This is also in line with the finding of other authors that performed similar investigations in the past [24], [25].

\section{CONCLUSION}

A PPT for nanosatellite application has been designed, built, and tested. As shown in Table VI, the PPT is compliant with all design requirements. The PPT mass was 30\% lower than the maximum allowable limit. Moreover, the unit provided reliable and repeatable performance throughout the test campaign, delivering a specific impulse in excess of the mission requirements of $\sim 18 \%$.

Preliminary measurements of the EM noise generated by the PPT were also performed. From the data collected, it can be inferred that the noise is mostly generated by the spark plug discharge and that the discharge energy seems to have little to no effect on the noise; rms values of the order of $2-3 \mathrm{~V}$ were measured.

Future works shall include a lifetime test campaign to demonstrate that the PPT is reliable and can deliver the required total impulse. Moreover, for the flight qualification of the unit, environmental tests, i.e., mechanical, electromagnetic compatibility and thermal cycling tests, shall be performed.

\section{ACKNOWLEDGMENT}

The authors would like to thank A. M. Perez and Dr. F. Guarducci for their invaluable help during the course of the project.

\section{REFERENCES}

[1] A. Mingo Pérez, M. Coletti, and S. B. Gabriel, "Development of a microthruster module for nanosatellite applications," in Proc. 32nd Int. Electr. Propuls. Conf., Wiesbaden, Germany, 2011.

[2] A. Mingo Pérez, M. Coletti, and S. B. Gabriel, "A micro PPT for nanosatellite applications: Design and experimental results," in Proc. 48th AIAA/ASME/SAE/ASEE Joint Propuls. Conf. Exhibit, Atlanta, GA, USA Jul./Aug. 2012.

[3] S. W. Janson, H. Helvajian, W. W. Hansen, and J. Lodmell, "Microthrusters for nanosatellites," in Proc. 2nd Int. Conf. Integr. Micro Nanotechnol. Space Appl. (MNT), Pasadena, CA, USA, 1999. 
[4] J. Köhler and S. Airey, The NEOMEx Strawman, Enabling a Microsystem-Based Nanospacecraft, document TEC-MMA/2008/74, no. 1,2008 .

[5] W. Johnson, "Definition and sizing of AOCS for NEOMEx nanosatellites: Final report," document SEA/10/TN/0049, no. 1, 2010.

[6] D. A. Gibbon, J. A. Ward, and N. Kay, "The design, development and testing of a propulsion system for the SNAP-1 nanosatellite," in Proc. 14th Anпи. AAIA/USU Small Satellite Conf., 2000.

[7] E. Peterson, J. Grzymisch, H. Spencer, R. E. Zee, and J. Arkani-Hamed, "The design of a lunar farside gravity mapping nanosatellite for the European student moon orbiter mission," in Proc. 21 st Annu. AAIA/USU Small Satellite Conf., 2007.

[8] N. G. Orr, J. K. Eyer, B. P. Larouche, and R. E. Zee, "Precision formation flight: The CanX-4 and CanX-5 dual nanosatellite mission," in Proc. 21 st Annu. AAIA/USU Small Satellite Conf., 2007.

[9] S. Eagleson, S. Mauthe, K. Sarda, H. Spencer, and R. E. Zee, "The MOMENT magnetic mapping mission Martian science on a nanosatellite platform," in Proc. 21st Annu. AAIA/USU Small Satellite Conf., 2007.

[10] M. Kameche, H. Benzeniar, A. B. Benbouzid, R. Amri, and N. Bouanani, "Disaster monitoring constellation using nanosatellites," J. Aerosp. Technol. Manag., São José dos Campos, vol. 6, no. 1, pp. 93-100, Jan./Mar. 2014

[11] P. Gessini and G. Paccani, "Ablative pulsed plasma thruster system optimization for microsatellites," in Proc. 27th Int. Electr. Propuls. Conf., 2001, paper IEPC-01-182.

[12] M. Coletti, F. Guarducci, and S. B. Gabriel, "A micro PPT for Cubesat application: Design and preliminary experimental results," Acta Astron., vol. 69, nos. 3-4, pp. 200-208, 2011.

[13] A. Nawaz, G. Herdrich, H. Kurtz, T. Schonherr, and M. Auweter-Kurtz, "SIMP-LEX: Systematic geometry variation using thrust balance measurements," in Proc. 30th Int. Electr. Propuls. Conf., Florence, Italy, Sep. 2007.

[14] S. Ciaralli, M. Coletti, F. Guarducci, and S. B. Gabriel, "PPTCUP lifetime test results," in Proc. 33rd Int. Electr. Propuls. Conf., Washington, DC, USA, Oct. 2013, paper IEPC-2013-164.

[15] S. Ciaralli, M. Coletti, and S. B. Gabriel, "An impulsive thrust balance for applications of micro-pulsed plasma thrusters," Meas. Sci. Technol., vol. 24, no. 11, p. 115003, 2013.

[16] R. L. Burton and P. J. Turchi, "Pulsed plasma thruster," J. Propuls. Power, vol. 14, no. 5, pp. 716-735, 1998.

[17] S. Ciaralli, M. Coletti, and S. B. Gabriel, " $\mu$-PPTs diagnostics: A high accuracy impulsive thrust balance," in Proc. 33rd Int. Electr. Propuls. Conf., Washington, DC, USA, Oct. 2013, paper IEPC-2013-165.

[18] M. Hirata and H. Murakami, "Electromagnetic noise measurement study of pulsed plasma engine," in Proc. AIAA/JSASS/DGLR 15th Int. Electr. Propuls. Conf., 1981.

[19] M. Begun and W. J. Guman, Pulsed Plasma Radio Frequency Interference Studies. Farmingdale, NY, USA: Fairchild, 1977.

[20] A. Plokhikh, N. Antropov, N. Vazhenin, G. Popov, G. Shishkin, and G. Soganova, "Electromagnetic emission of pulsed plasma thrusters," in Proc. 20th Int. Zürich Symp. Electromagn. Compat., Jan. 2009, pp. 21-24.

[21] C. Zakrzwski, S. Benson, J. Cassidy, and P. Sanneman. (2002). Pulsed Plasma Thruster (PPT) Validation Report. [Online]. Available: http://eo1.gsfc.nasa.gov/new/validationReport/

[22] C. Zakrzwski and S. Benson, "Section 25: EO-1 pulsed plasma thruster," EO-1 Mission Technology Forum, Greenbelt, MD, USA, Tech. Rep., 2001.
[23] S. W. Benson, L. A. Arrington, W. A. Hoskins, and N. J. Meckel, "Development of a PPT for the EO-1 spacecraft," in Proc. 35th AIAA/ASME/SAE/ASEE Joint Propuls. Conf. Exhibit, 1999.

[24] W. A. Hoskins, C. Rayburn, and C. Sarmiento, "Pulsed plasma thruster electromagnetic compatibility: History, theory and the flight validation on EO-1," in Proc. 39th AIAA/ASME/SAE/ASEE Joint Propuls. Conf. Exhibit, 2003.

[25] K. I. Thomassen, "Radiation from pulsed plasma thruster," J. Spacecraft, vol. 7, no. 7, pp. 889-890, 1970.

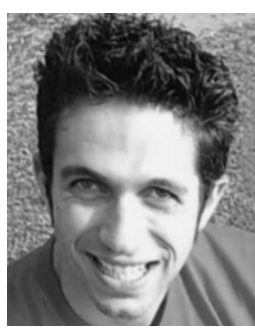

Michele Coletti received the B.Sc. and M.Sc. degrees in aerospace engineering from the University of Rome La Sapienza, Rome, Italy, in 2003 and 2005 , respectively, and the Ph.D. degree in electric propulsion from the University of Southampton, Southampton, U.K., in 2008.

$\mathrm{He}$ is currently the Director of Mars Space Ltd., Southampton, where he is in charge of all research and development activities, including research and development on hollow cathodes, hollow cathodes thrusters, high-power gridded ion engines, and micro pulsed plasma thruster for cubesat and nanosatellites applications.

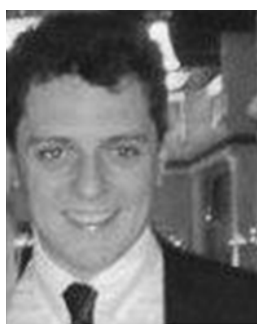

Simone Ciaralli received the B.Sc. (Hons.) degree in aerospace engineering and the M.Sc. (Hons.) degree from the University of Rome La Sapienza, Rome, Italy, in 2008 and 2011, respectively. He is currently pursuing the Ph.D. degree in electric space propulsion with the University of Southampton, Southampton, U.K., with a focus on the optimization of pulse plasma thrusters performance. His Ph.D. research is sponsored by Mars Space Ltd., Southampton

Stephen B. Gabriel is currently a Professor of Aeronautics and Astronautics with the University of Southampton, Southampton, U.K., and the Managing Director of Mars Space Ltd., Southampton. Between the 80s and 90s, he was with Jet Propulsion Laboratory (JPL), Pasadena, CA, USA, becoming the Group Supervisor of the Natural Space Environments at the Reliability Engineering Section being responsible for all natural space environment inputs to JPL missions, including Galileo, Cassini, Topex, and Mars Observer. $\mathrm{He}$ is also involved in several EP technologies, including but not limited to gridded ion engines, pulsed plasma thruster, MPD thruster, hollow cathodes, and colloids. 